\title{
Recent developments in materials for potentiometric sensors
}

\author{
J. Zosel $I^{1}$, M. Schelter ${ }^{1}$, W. Oelßner ${ }^{1}$, C. Vonau ${ }^{1}$, U. Enseleit ${ }^{1}$, V. Vashook ${ }^{2}$, D. Tuchtenhagen ${ }^{3}$, \\ K. Wienand ${ }^{4}$, U. Guth ${ }^{1,2}$, M. Mertig ${ }^{1,2}$ \\ ${ }^{1}$ Meinsberg Kurt-Schwabe Research Institute, Kurt-Schwabe-Str. 4, \\ 04720 Ziegra-Knobelsdorf, Germany, \\ zosel@ksi-meinsberg.de \\ ${ }^{2}$ Technische Universität Dresden, Institute for Physical Chemistry, \\ 01062 Dresden, Germany \\ ${ }^{3}$ ACEOS GmbH, Karolinenstr. 108, 90763 Fürth, Germany \\ ${ }^{4}$ Heraeus Sensor Technology GmbH, Reinhard-Heraeus-Ring 23, 63801 Kleinostheim, Germany
}

\begin{abstract}
Electrochemical gas sensors based on Yttria Stabilized Zirconia (YSZ) with mixed potential electrodes are suited for in-situ measurements of low concentrations of combustibles like hydrogen, carbon monoxide, hydrocarbons and also nitrogen oxides. The parameters sensitivity, selectivity and long-term stability of these sensors are correlated mainly with the performance of the electrode material. The contribution will give an overview about recent developments on materials for that purpose. Examples, which are presented in more detail, concern polymer composite materials (CPC) and surface modified $\mathrm{Au} / \mathrm{Pt}$ alloy materials for mixed potential sensors. The materials have been characterized with respect to their morphology, thermal stability, catalytic activity and electrochemical behaviour on solid electrolytes in gases containing hydrogen, ethene and propene. For the first time it could be demonstrated, that CPC, consisting of polyaniline and different metal oxides or metal salts can be used at high temperature measurement up to temperatures of $450{ }^{\circ} \mathrm{C}$ b ecause of improved thermal properties.
\end{abstract}

Key words: conductive polymer composite, solid electrolyte, potentiometric gas sensor, mixed potential

\section{Introduction}

Electrochemical solid electrolyte sensors are suited for the reliable, highly sensitive and rapid measurement of different gases in hot environments and also applications at lower temperatures [1]. Important sensor parameters like sensitivity, selectivity and long-term stability are correlated mainly with the performance of the electrode material [2]. During the last two decades extensive efforts were directed especially on the development of new electrode materials for mixed potential sensors (MPS) [3-5], which are based on the kinetically controlled electrochemical conversion of oxidisable gases with oxide ions from the solid electrolyte $[3,4]$. Despite this intensive work there is still a considerable variety of attractive applications for these sensors, which cannot be addressed due to insufficient sensor performance. One of the most important issues concerns the long-term stability $[6,7]$, which is still critical for some of the electrode materials developed till now if measuring times of several months without calibration are strived for. Therefore, new con- ductive fillers for composite materials for mixed potential electrodes were developed, which provide sufficient electrochemical activity, thermal stability and low catalytic activity. Another direction of development in this field of materials concerns the surface modification to enhance selectivity of MPS [8]. Examples presented in more detail concern polymer composite materials (CPC) and Au/Pt alloy materials for trace gas analysis with MPS.

The CPC materials were made of conductive polyaniline (PANI) filled with different metal oxides or salts such as $\mathrm{Nb}_{2} \mathrm{O}_{5}$ or $\mathrm{FeCl}_{3}$ and $\mathrm{Co}\left(\mathrm{NO}_{3}\right)_{2}$ during the polymerization process. Intrinsically conducting polymers such as PANI have been the subject of extensive theoretical and experimental studies in recent years [9]. By filling the polymer with i.e. metal oxides, the thermal stability of the resulting CPC could be improved significantly. Because of its relatively high thermal stability, low costs, ease of synthesis and good environmental behaviour, among the conductive polymers PANI is most suited for this purpose $[10,11]$. 
$\mathrm{Au}$ and $\mathrm{Au} / \mathrm{Pt}$ composite materials based on $\mathrm{Ga}_{2} \mathrm{O}_{3}, \mathrm{Ta}_{2} \mathrm{O}_{3}$ [12] and $\mathrm{Nb}_{2} \mathrm{O}_{5}$ [13] showed advantages for the detection of very low concentrations of carbon monoxide and hydrocarbons.

Investigations on thermal stability, structure and morphology, catalytic activity and sensing behaviour in different non equilibrated gas mixtures also in correlation to their impedances underline the complex structure of signal generation on this kind of sensors. One possible application of MPS is directed on the monitoring of climacteric fruit maturation processes depending on the ethene concentration.

\section{Experimental}

One group of composite materials for MPS were made of a composite containing the conducting polymer polyaniline (PANI) and $\mathrm{Nb}_{2} \mathrm{O}_{5}$ or $\mathrm{FeCl}_{3} / \mathrm{Co}\left(\mathrm{NO}_{3}\right)_{2}$ salt mixture respectively. The second group was manufactured from $\mathrm{Au} / \mathrm{Pt}$ alloys with $\mathrm{ZrO}_{2}$ nanoparticles and surface modified with $\mathrm{Rh}$, Ir and Ru salts. All materials were characterized with SEM, TEM, XRD, XPS, BET and DTA. Pastes were made by mixing the powders with an organic binder and screen printed on stabilized zirconia slices.

In case of PANI based materials the screen printed electrodes were dried $2 \mathrm{~h}$ at $250{ }^{\circ} \mathrm{C}$ and electrochemically tested by means of potentiometric and impedimetric measurements in $\mathrm{N}_{2}$ with $1.5 \mathrm{vol} \% \mathrm{O}_{2}$ containing $0 \ldots 900$ vol.-ppm $\mathrm{H}_{2}$ or $\mathrm{C}_{3} \mathrm{H}_{6}$ respectively.

The alloy based composite electrodes were screen printed on YSZ sheets and fired at $1000{ }^{\circ} \mathrm{C}$ over $1 \mathrm{~h}$. Subsequently, surfaces were modified with $\mathrm{ZrO}_{2}$ nanoparticles by sputtering $\mathrm{Zr}$ onto the electrodes and sintering the electrodes in a highly oxidizing atmosphere. Additionally some surfaces were sprayed with highly diluted salt solutions containing $\mathrm{Rh}$, Ir and $\mathrm{Ru}$ salts. After drying and firing the salty layers in reducing atmospheres at these surfaces $\mathrm{Rh}$, Ir and $\mathrm{Ru}$ particles, respectively, were formed. The aim of those modifications was the forming of small spots on the electrode surface with modified catalytic activity to change the electrode response in different gases.

Additionally the catalytic activity was measured in propene at temperatures between $200 \ldots 800^{\circ} \mathrm{C}$ by using the setup described elsewhere [14].

Miniaturised sensors as shown in Fig. 1 were developed for ethene measurement in atmospheres for fruit storage. Investigations were carried out therefore in model mixtures containing 4 vol- $\% \mathrm{O}_{2}, 7.2$ vol.- $\% \mathrm{CO}_{2}$ and $0 \ldots 19$ vol.ppm $\mathrm{C}_{2} \mathrm{H}_{4}$.

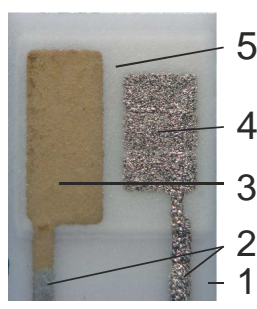

A

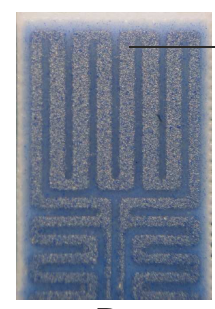

B

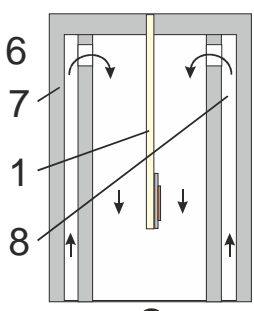

C
Fig. 1. Design of the sensor, A) detail of the alumina substrate 1 with Pt-connecting pads 2, Au/MeOelectrode 3, Pt-reference electrode 4 and YSZelectrolyte 5; B) Pt-heater 6; C) double chamber housing 7 with sensor and pathway of preheated gas flow 8 , substrate dimensions: $3 \times 15 \mathrm{~mm}^{2}$

\section{Results}

\section{Structure}

The preparations of pure PANI as well as those of the composites result in agglomerates. The metal salt containing composite looks similar to pure PANI, leading to the assumption that the metal ions build an intercalation compound with the polymer. The metal oxide containing composite confirms the assumption that PANI is adsorbed at the $\mathrm{Nb}_{2} \mathrm{O}_{5}$ particles. Examples of TEM images given in Fig. 2 illustrate differences of the particle encasement between samples prepared by adding the $\mathrm{Nb}_{2} \mathrm{O}_{5}$ before or after starting of the polymerization respectively. The grain sizes of the different composites are distributed around $0.5 \mu \mathrm{m}$ in case of the metal oxide containing CPC and around 1 $\mu \mathrm{m}$ for the metal salt containing CPC.

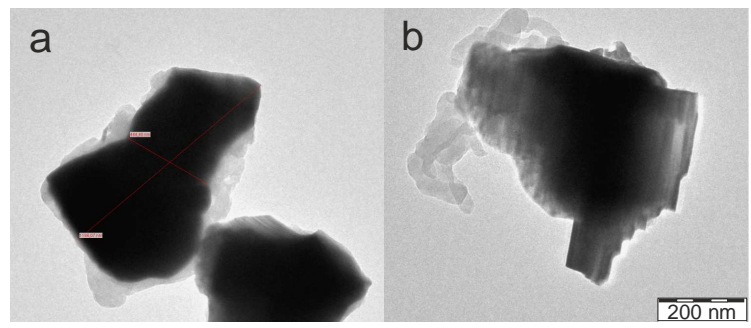

Fig. 2. TEM images of $\mathrm{Nb}_{2} \mathrm{O}_{5}$ containing PANI composites; a) oxide added before start of polymerisation, b) oxide added during polymerisation

\section{Thermal behaviour}

Adequate thermal stability of pure PANI is limited to temperatures below $250^{\circ} \mathrm{C}$. Thermogravimetric investigations indicate that the addition of $\mathrm{Nb}_{2} \mathrm{O}_{5}$ increases the thermal stability significantly, resulting in the reduced weight loss $12 \%$ at $500 \%$ (Fig. 3). As it can also be seen from Fig. 4, the composite with metal oxide added before starting the polymerisation shows a slightly higher thermal stability than the composite with $\mathrm{Nb}_{2} \mathrm{O}_{5}$ added after start of polymerisation, which might be related to the incomplete PANI covering of $\mathrm{Nb}_{2} \mathrm{O}_{5}$ grains. 


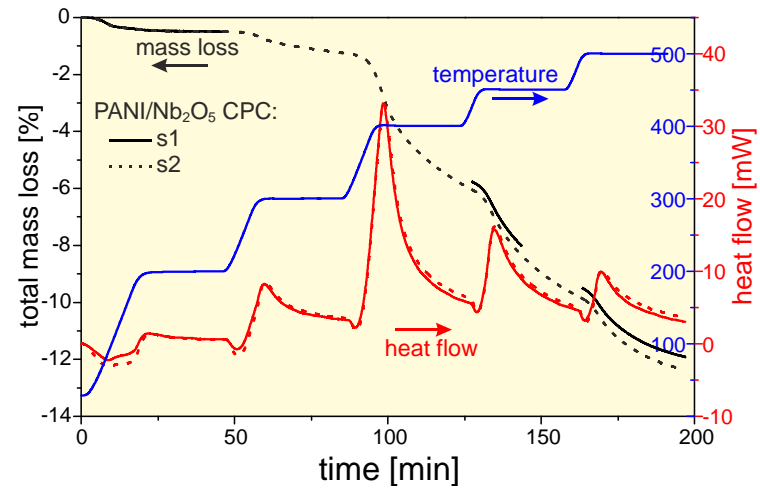

Fig. 3. Thermal characterisation curves $\mathrm{Nb}_{2} \mathrm{O}_{5}$ containing samples: s1: oxide added before start of polymerisation, s2: oxide added after start of polym.

The reasons for thermal stabilisation have to be clarified in detail in future investigations. The metal oxide containing composites have been changed their colours from blue/white to grey/white, although it was verified that PANI remains in the composite.

\section{Catalytic behaviour}

Catalytic activities of electrode materials for the oxidation of the gaseous components to be measured with MPS influence their sensitivity and gas consumption significantly [14]. This complementary investigation can be carried out to screen promising electrode materials. Fig. 4 shows significant differences between the investigated materials. The $\mathrm{CPC}$ with a more acidic character show higher catalytic activities than the ones prepared by intensive washing.

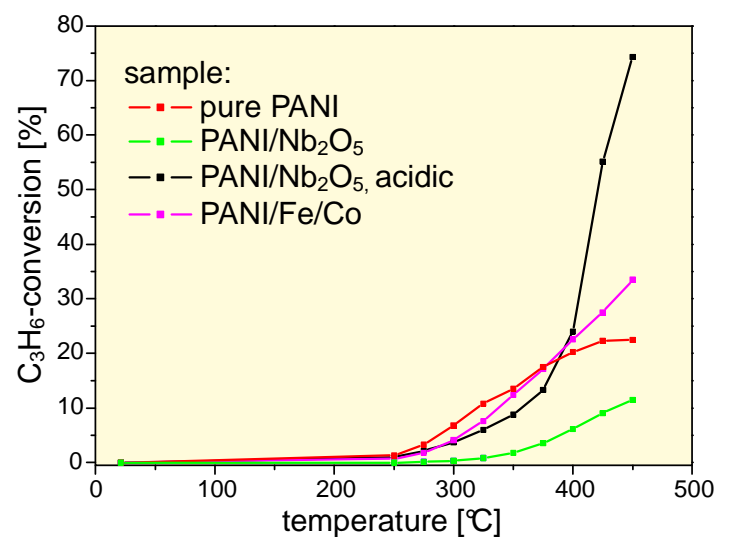

Fig. 4. Catalytic activity of investigated materials to propene conversion, acidic $\mathrm{Nb}_{2} \mathrm{O}_{5} \mathrm{CPC}$ washed till colour change of precipitate

\section{Potentiometric response}

While the metal oxides and salts in the composites are responsible for oxygen exchange with the gas phase and the solid electrolyte, catalytic behaviour and thermal stabilisation, the PANI in the composites plays an important role for electrode conductivity. The interactions between niobium oxide and polyaniline may reflect their chemical identities. If the acidity is not too strong, anionic niobate may exist at the interface with positively charged PANI species.

The results of the CPC materials show that the logarithmic response expected from the mixed potential theory [3] is established at concentrations above 100 vol.-ppm, as the example given in Fig. 5 for response to $\mathrm{H}_{2}$ indicates. At the concentrations 10 vol.-ppm $\left(\mathrm{H}_{2}\right.$ and $\left.\mathrm{C}_{3} \mathrm{H}_{6}\right)$ and 1 vol.-ppm $\left(\mathrm{C}_{2} \mathrm{H}_{4}\right)$ the sensitivities range between 0.6 ... $8.5 \mathrm{mV} / \mathrm{vol}$.-ppm.

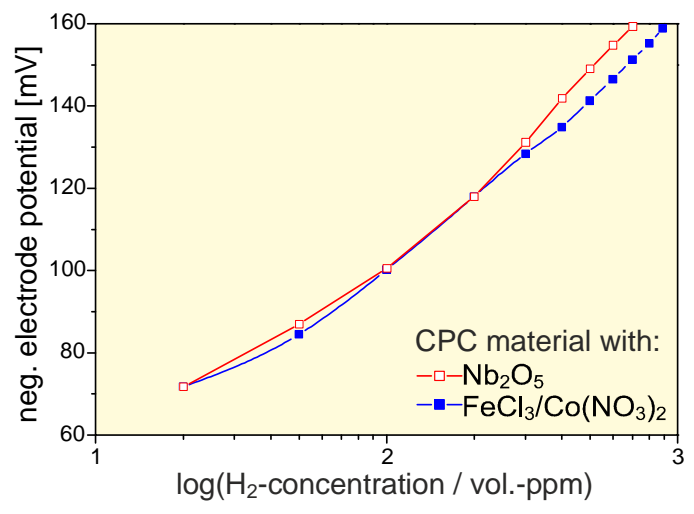

Fig. 5. Potentiometric response for $\mathrm{H}_{2}$ of some investigated CPC materials

One example of the potentiometric response of the alloy based electrodes given in Fig. 6 underlines, that it is possible to establish also elevated sensitivities to $\mathrm{NO}_{2}$ on surface modified electrodes. The maximum sensitivity depending on the $\mathrm{Au} / \mathrm{Pt}$ ratio is shifted to higher $\mathrm{Pt}$ concentrations when the material was surface modified with $\mathrm{ZrO}_{2}$-nanoparticles.

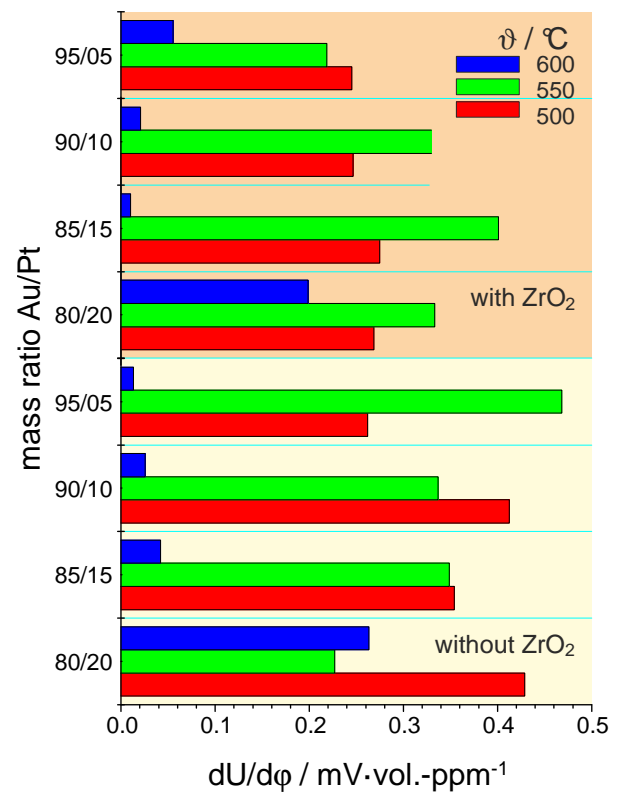

Fig. 6. $\mathrm{NO}_{2}$-Sensitivities (at $100 \mathrm{vol}$-ppm) of Au/Ptcomposite electrodes to $\mathrm{NO}_{2}$-containing gas with $1.5 \mathrm{vol} . \% \mathrm{O}_{2}$ in $\mathrm{N}_{2}$ at different temperatures. 
A possible field of application of MPS concerns the detection of hydrocarbon traces in oxygen containing atmospheres. One example known from literature is the monitoring of fruit storage atmospheres to control fruit maturation. For climacteric fruits the measurement of ethene at concentrations below $10 \mathrm{ppm}$ is required. The curves in Fig. 7 demonstrate that MPS with a gas symmetrical design according to Fig. 1 can be utilized for that purpose with sensitivities above $0.5 \mathrm{mV} / \mathrm{vol}$.-ppm. Investigations on the selectivity in controlled atmospheres with fruits are planned for the near future.

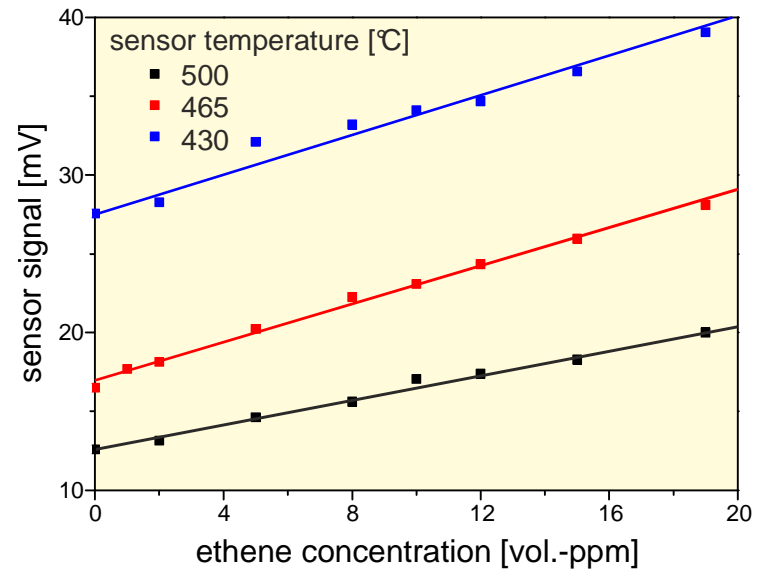

Fig. 7. Response of a sensor with $\mathrm{Au} / \mathrm{Ga}_{2} \mathrm{O}_{3}$ composite electrode according to Fig. 1 to ethene in a fruit storage atmosphere containing 4 vol.- $\% \mathrm{O}_{2}$ and 7.2 vol. $-\% \mathrm{CO}_{2}$

\section{Conclusions}

New composite materials based on polyaniline and surface modified Au/Pt alloys have been prepared and tested successfully as mixed potential electrodes of YSZ based solid electrolyte sensors in hydrogen and hydrocarbons $\left(\mathrm{C}_{3} \mathrm{H}_{6}\right.$ and $\left.\mathrm{C}_{2} \mathrm{H}_{4}\right)$ at temperatures between 400 and $600{ }^{\circ} \mathrm{C}$. Different types of synthesised PANI composites with $\mathrm{Nb}_{2} \mathrm{O}_{5}$ or $\mathrm{FeCl}_{3} / \mathrm{Co}\left(\mathrm{NO}_{3}\right)_{2}$ showed enhanced sensitivity. The measured sensitivities do not correlate with the catalytic behaviour of the composites due to large differences of the specific conductivities. The implementation of $\mathrm{Nb}_{2} \mathrm{O}_{5}$ causes remarkable thermal stabilisation of CPC.

Four different Au/Pt alloys were prepared and surface modified with $\mathrm{ZrO}_{2}-, \mathrm{Rh}-, \mathrm{Ir}-$ and $\mathrm{Ru}$ nanoparticles. The materials show enhanced sensitivities to $\mathrm{CO}, \mathrm{C}_{3} \mathrm{H}_{6}$ and $\mathrm{NO}_{2}$. Complementary investigations of conductivity and catalytic activity underline the complex structure of signal generation at mixed potential gas sensors.

\section{Acknowledgement}

Parts of this contribution were based on a project supported financially by the German Fed- eral Ministry of Economics and Technology (support code KF2218309AK0). The authors responsible for the content of the paper thank gratefully for financial support.

\section{References}

[1] V. Plashnitsa et al., $\mathrm{NO}_{2}$ sensing performances of planar sensor using stabilized zirconia and thin$\mathrm{NiO}$ sensing electrode, Sens. Actuators B 130, 231-239 (2008)

[2] J. Zosel et al., Perovskite related electrode materials with enhanced NO sensitivity for mixed potential sensors, Solid State lonics 179, 1628-1631 (2008)

[3] N. Miura et al., Highly selective CO sensor using stabilized zirconia and a couple of oxide electrodes, Sens. Actuators B 47, 84-91 (1998)

[4] F. H. Garzon et al., Solid-state mixed potential gas sensors: theory, experiments and challenges, Solid State Ionics 136-137, 633-638 (2000)

[5] S. Käding et al., YSZ-cells for potentiometric nitric oxide sensors, lonics 9, 151-154 (2003); DOI: 10.1007/BF02376552

[6] E. L. Brosha et al., Mixed potential sensors using lanthanum manganate and terbium yttrium zirconium oxide electrodes, Sens. Actuators B87, 4757 (2002)

[7] D. Schönauer et al., Selective mixed potential ammonia exhaust gas sensor, Sens. Actuators B140, 585-590 (2009)

[8] P. Elumalai et al., Highly sensitive and selective stabilized zirconia-based mixed-potential-type propene sensor using $\mathrm{NiO} / \mathrm{Au}$ composite sensingelectrode, Sens. Actuators B144, 215-219 (2010)

[9] C. Basavaraja et al., Synthesis, characterization, and comparative study of conducting polyaniline/lead titanate and polyanilinedodecylbenzenesulfonic acid/lead titanate composites, J. Appl. Polym. Sci. 108, 1070-1078 (2008); DOI: 10.1002/app.27582

[10] A. Pud et al., Some aspects of preparation methods and properties of polyaniline blends and composites with organic polymers, Prog. Polym. Sci. 28, 1701-1753 (2003);

[11] T. A. Skoheim, R. L. Elsenbaumer, J. R. Reynolds, Handbook of Conducting Polymers, 1998, Marcel Dekker, New York

[12] J. Zosel et al., Au/Oxide Composites as HC Sensitive Electrode Material for Mixed Potential Gas Sensors, Solid State Ionics 152-153, 525-529 (2002);

[13] T. Hibino et al., Non-Nernstian Behavior at Modified Au Electrodes for Hydrocarbon Gas Sensing, J. Electrochem. Soc. 146, 3361-3366 (1999)

[14] R. Müller et al., Investigations on Selected Gallium and Strontium Doped Lanthanum Chromites as Electrode Materials for HC Detection, Ionics 8, 262-266 (2002) 